\title{
TRIBOLOGICAL STUDY OF SELF-LUBRICATING COMPOSITES WITH HEXAGONAL BORON NITRIDE AND GRAPHITE AS SOLID LUBRICANTS*
}

\author{
Kelen Juliane Mucelin ${ }^{1}$ \\ Priscila da Costa Gonçalves ${ }^{1}$ \\ Gisele Hammes ${ }^{1}$ \\ Roberto Binder ${ }^{2}$ \\ Rolf Janssen ${ }^{3}$ \\ Aloisio Nelmo Klein ${ }^{1}$ \\ José Daniel Biasoli de Mello4
}

\begin{abstract}
In order to better understand the tribological behavior of self-lubricating materials, $\mathrm{Fe}$ Si-C matrix composites containing solid lubricants added during the mixing step were studied. The samples were produced by conventional powder metallurgy route, presenting total contents of $5 \%, 7.5 \%$ and $10 \%$ in volume of $\mathrm{h}-\mathrm{BN}$ and graphite mixtures as solid lubricants. The composites were evaluated in terms of tribological properties, under reciprocating sliding conditions, and mechanical properties by using tensile tests. Additionally, the wear scars were characterized by Raman spectroscopy and scanning electronic microscopy. Higher total contents of solid lubricants greatly increased scuffing resistance however decreased mechanical properties. Furthermore, increasing h-BN contents reduces both properties. These results confirmed the applicability of such sintered composites as self-lubricating parts, reaching values up to $7000 \mathrm{~N} . \mathrm{m}$ for scuffing resistance combined with ultimate tensile strength of $220 \mathrm{MPa}$.
\end{abstract}

Keywords: Scuffing resistance; Powder metallurgy; h-BN; Graphite.

1 Materials Laboratory (LabMat), Federal University of Santa Catarina (UFSC), Florianópolis, SC, Brazil.

2 Whirlpool- Embraco Unit, Joinville, SC, Brazil.

3 Technische Universität Hamburg-Harburg, Institute of Advanced Ceramics, Hamburg, Germany.

4 UFSC, Laboratory of Tribology and Materials (LTM), School of Mechanical Engineering, Federal University of Uberlândia (UFU), Uberlândia, MG, Brazil.

* Technical contribution to the $2^{\text {nd }}$ International Brazilian Conference on Tribology - TriboBR 2014, November $3^{\text {rd }}$ to $5^{\text {th }}$, 2014, Foz do Iguaçu, PR, Brazil. 


\section{INTRODUCTION}

The evolution of advanced technology, social growth and concerns about the environment are driving the search for quality, economy and efficiency of new products. The development of advanced materials leads to improvements of products properties as high efficiency, low energy consumption, light weight, high strength, improved performance, longer product life, and others. [1]

Within this context, the development of tribological systems increasing, as a result of the huge cost of tribological deficiencies, caused by the large amount of energy losses by friction that occur in every mechanical device in operation. [2]

In order to minimize losses by friction in the contact surfaces under relative motion, lubricants are widely used, the commonly applied are fluid lubricants, and greases. However solid lubricants can be used as an alternative to the liquid lubrication in situations where its use is not possible or efficient. Some solid lubricants have a lamellar structure, such as graphite and h-BN, which consists of a stack of hexagonal sheets or layers with strong covalent bonds between the atoms in each layer, however the layers are held together by weak Van der Waals forces. This structure allows shearing when force is applied parallel to the layers. Thus, it provides the expected friction reduction and results in very efficient lubrication [3]. Solid lubricants can be used to manufacture self-lubricating materials, which are composite materials with solid lubricant incorporated in the matrix volume. These composite materials can be easily produced by using powder metallurgy that has been widely used for producing parts in the industry, mainly because of its low cost when applied to large volume production and great versatility [4].

This work presents the influence of $h-B N$ and graphite mixtures as solid lubricants on the tribological behavior of self-lubricating composites based on a Fe-Si-C matrix produced by powder metallurgy.

\section{MATERIAL AND METHODS}

In order to study the tribological behavior of sintered self-lubricating composites, samples were produced using iron (Höganäs, AHC 100.29) and silicon (Osprey Sandvik, alloy Fe45Si) as major constituents of the matrix, furthermore graphite (Nacional de Grafite, Micrograph 99545HP) and hexagonal boron nitride (Momentive, AC6028) were added during the mixing step as solid lubricants. The mixture compositions are presented in Table 1. Two parameters were varied: total content of solid lubricant in volume $(5 \%, 7.5 \%$ and $10 \%)$ and $\mathrm{h}$-BN content in the volume $(1 \%$, $1.75 \%$ and $2.5 \%$ ), the graphite content was used as a balance. The powders were mixed in a Y-type mixer during 45 minutes with 35 RPM of rotation, with 0.8 weight\% of amide wax to assist during the pressing stage. The powder mixtures were uniaxially pressed at $600 \mathrm{MPa}$ using a double-action press with floating die, producing samples for tensile tests according to MPIF 35 Standard, cylindrical samples for microstructural analyzes $(\varnothing 10 \mathrm{~mm}$ per $6 \mathrm{~mm})$ and tribological tests $(\varnothing$ $20 \mathrm{~mm}$ per $5 \mathrm{~mm}$ ). These samples were sintered at $1120{ }^{\circ} \mathrm{C}$ during one hour in a resistive furnace under controlled atmosphere (95\% argon and 5\% hydrogen), using a heating rate of $10^{\circ} \mathrm{C} / \mathrm{min}$ and a debinding step at $500{ }^{\circ} \mathrm{C}$ during 30 minutes. The microstructural analyzes were performed by optical microscopy (Olympus BX60) after metallographic preparation of the samples. The tensile tests were carried out on an universal testing machine (MTS, Model 810) in accordance with the MPIF 35 Standard.

\footnotetext{
* Technical contribution to the $2^{\text {nd }}$ International Brazilian Conference on Tribology - TriboBR 2014, November $3^{\text {rd }}$ to $5^{\text {th }}, 2014$, Foz do lguaçu, PR, Brazil.
} 
Table 1. Table of mixtures composition

\begin{tabular}{|c|c|c|c|c|c|}
\hline Mixture & $\begin{array}{l}\text { Total content of solid } \\
\text { lubricant (Vol\%) }\end{array}$ & h-BN (Vol\%) & $\begin{array}{c}\mathrm{C} \\
(\text { Vol\%) }\end{array}$ & $\begin{array}{c}\mathrm{Si} \\
\text { (weight\%) }\end{array}$ & $\begin{array}{c}\mathrm{Fe} \\
\text { (weight\%) }\end{array}$ \\
\hline $1 \mathrm{~h} 4 \mathrm{C}$ & \multirow{3}{*}{5} & 1 & 4 & \multirow{9}{*}{0.5} & \multirow{9}{*}{ Balance } \\
\hline $1.75 \mathrm{~h} 3.25 \mathrm{C}$ & & 1.75 & 3.25 & & \\
\hline $2.5 \mathrm{~h} 2.5 \mathrm{C}$ & & 2.5 & 2.5 & & \\
\hline $1 \mathrm{~h} 6.5 \mathrm{C}$ & \multirow{3}{*}{7.5} & 1 & 6.5 & & \\
\hline $1.75 \mathrm{~h} 5.75 \mathrm{C}$ & & 1.75 & 5.75 & & \\
\hline $2.5 \mathrm{~h} 5 \mathrm{C}$ & & 2.5 & 5 & & \\
\hline $1 \mathrm{~h} 9 \mathrm{C}$ & \multirow{3}{*}{10} & 1 & 9 & & \\
\hline $1.75 \mathrm{~h} 8.25 \mathrm{C}$ & & 1.75 & 8.25 & & \\
\hline $2.5 \mathrm{~h} 7.5 \mathrm{C}$ & & 2.5 & 7.5 & & \\
\hline
\end{tabular}

Reciprocating sliding tests were carried out in a tribometer (CETR UMT-3) in an incremental loading mode (increasing the normal load in increments of $7 \mathrm{~N}$ at every 10 minutes intervals). A steel sphere (AISI 52100, $\varnothing 5 \mathrm{~mm}$ ) was fixed on a pivoted arm against the non-tested sample surface under constant frequency $(2 \mathrm{~Hz})$ and constant stroke $(10 \mathrm{~mm})$. In this study, the scuffing resistance was defined as the work (N.m) at which the value of the friction coefficient first reaches 0.2. At least seven samples of each material were tested. Wear scars were investigated by scanning electronic microscopy (SEM - JEOL JSM-6390LV) and micro-Raman spectroscopy (Renishaw InVia) with argon laser $(\lambda=514.5 \mathrm{~nm})$.

\section{RESULTS AND DISCUSSION}

In Figure 1, typical aspect of the samples microstructures produced with different total solid lubricant contents (5\%,7.5\% and $10 \%)$ are presented. An increase of solid lubricant reservoirs, regularly distributed in the metallic matrix, can be noted, as expected, when increasing the total solid lubricant content.

* Technical contribution to the $2^{\text {nd }}$ International Brazilian Conference on Tribology - TriboBR 2014, November $3^{\text {rd }}$ to $5^{\text {th }}$, 2014, Foz do Iguaçu, PR, Brazil. 

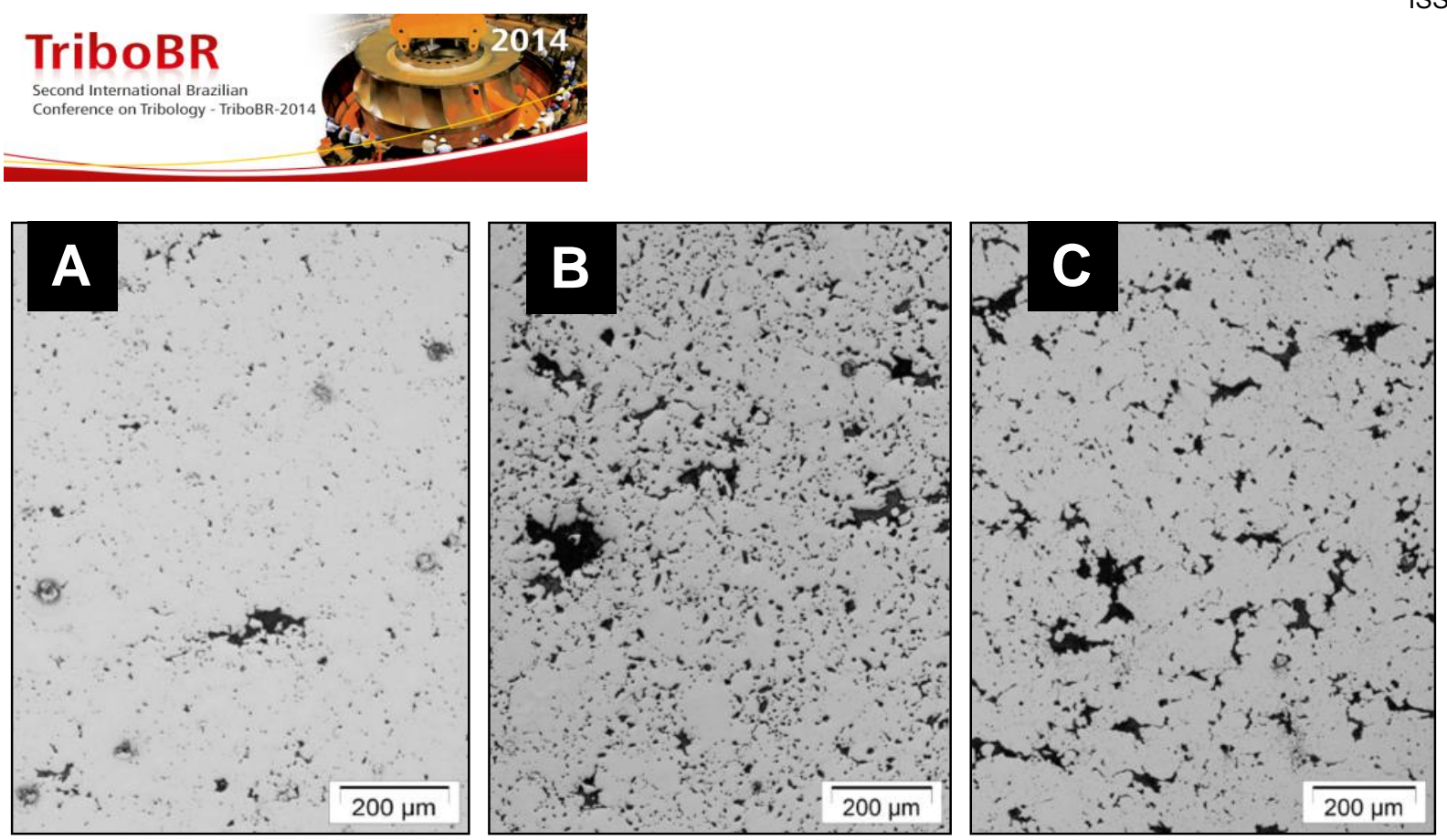

Figure 1. Non-etched micrographs obtained by optical microscopy, micrograph A- sample 1h4C, Bsample $1 \mathrm{~h} 6.5 \mathrm{C}, \mathrm{C}$ - sample $1 \mathrm{~h} 9 \mathrm{C}$. The dark regions represent h-BN, graphite and porosity.

Figure 2 shows tensile strength of the composites. It can be observed that as the total amount of solid lubricant increased, the tensile strength decreased. Besides, a reduction within the three levels of total solid lubricant was also observed, due to increased amounts of $\mathrm{h}$-BN. The solid lubricant reservoirs may be considered discontinuities in the iron based matrix, then, as the percentage of solid lubricants increases, the discontinuity of the matrix also rises, leading to the reduction of the tensile strength, as observed.

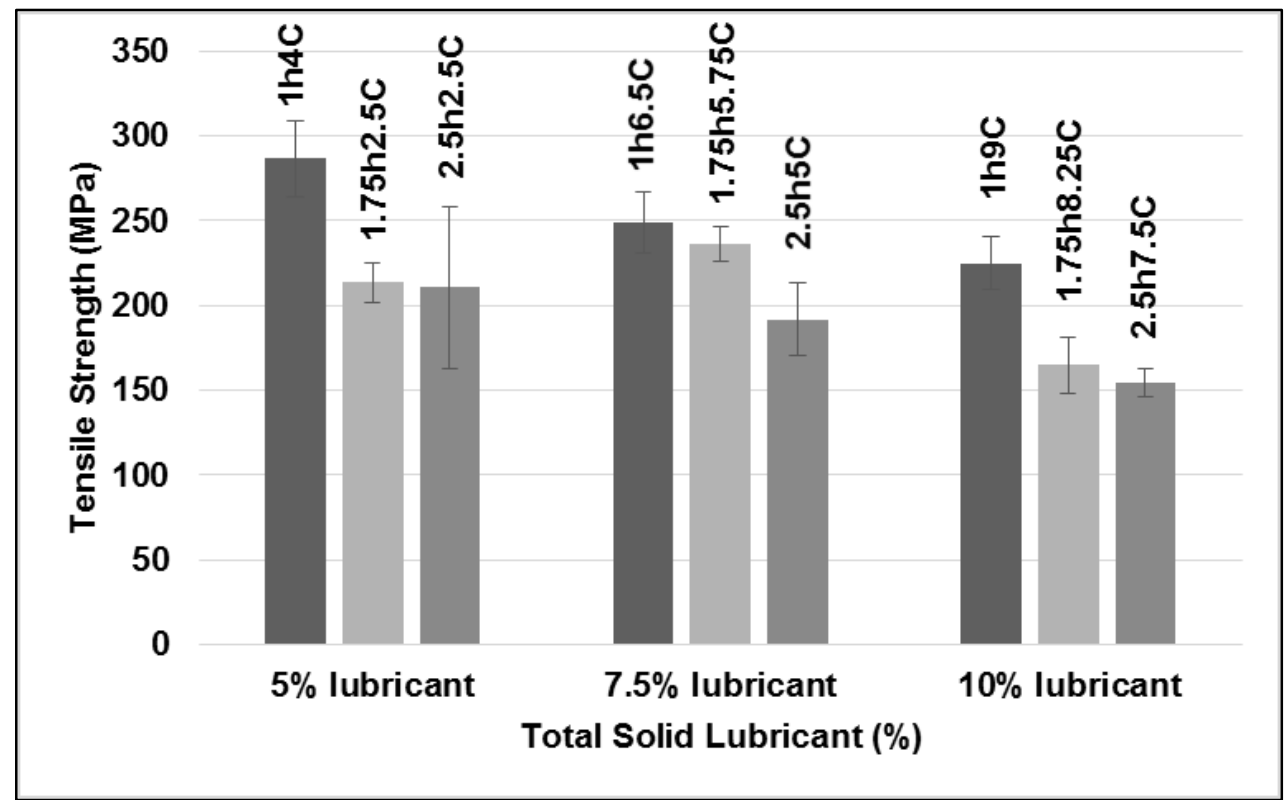

Figure 2. Tensile strength of sintered composites as function of $\mathrm{h}-\mathrm{BN}$ content and total content of solid lubricant.

Typical etched microstructures presenting $5 \%$ and $10 \%$ of total solid lubricant can be observed in Figure 3. The sample containing the highest amount of solid lubricant (Fig.3B) also presents higher amount of graphite, which diffuses into the matrix, favoring the formation of perlite and cementite.

\footnotetext{
* Technical contribution to the $2^{\text {nd }}$ International Brazilian Conference on Tribology - TriboBR 2014, November $3^{\text {rd }}$ to $5^{\text {th }}$, 2014, Foz do Iguaçu, PR, Brazil.
} 

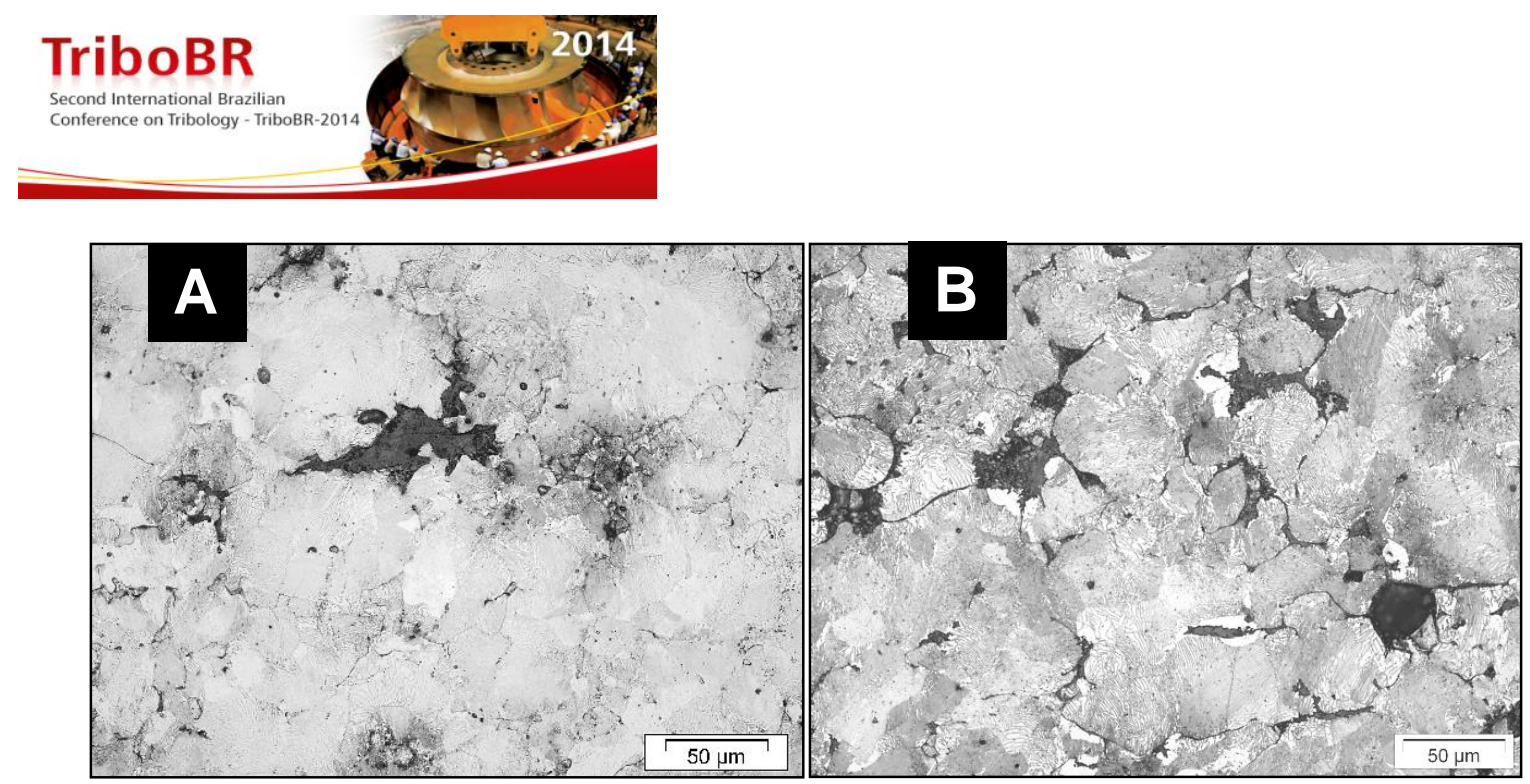

Figure 3. Microstructures of the samples containing $5 \mathrm{Vol} \%$ and $10 \mathrm{Vol} \%$ of solid lubricant respectively. A- sample 1h4C. B- sample1h9C.

The typical behavior of friction coefficient of three composites presenting $5 \%, 7.5 \%$, and 10 Vol\% of solid lubricant is shown in Figure 4. The sample with $5 \%$ of solid lubricant content showed a significant increase of the friction coefficient, above the line of the lubricious regime, at the beginning of the test. In these conditions, this composite cannot be considered a self-lubricating material. However, the friction coefficient of samples with $7.5 \%$ and $10 \%$ of total solid lubricant content remained longer within the lubricious regime, bellow 0.2. Thus, under these conditions, the composites with $7.5 \%$ and $10 \%$ of total solid lubricant can be termed self-lubricating materials.

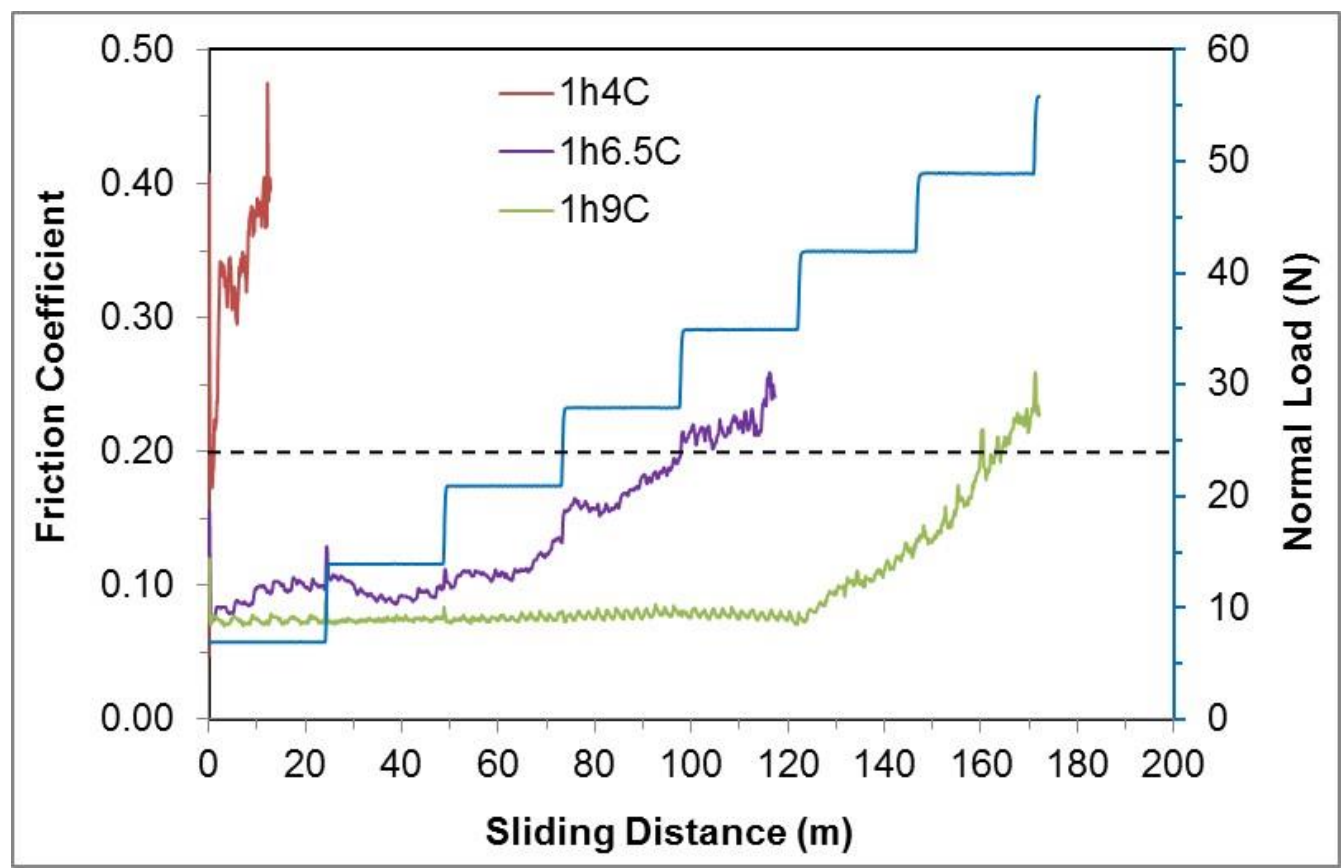

Figure 4. Typical evolution of friction coefficient with test time for three levels of total solid lubricant (5, 7.5 and $10 \%)$.

Figure 5 illustrates the conjoint effect of total solid lubricant content $(7.5 \%$ and $10 \%)$ and $\mathrm{h}-\mathrm{BN}$ content ( $1 \%$ and $2.5 \%$ ) on friction coefficient evolution with test time.

\footnotetext{
* Technical contribution to the $2^{\text {nd }}$ International Brazilian Conference on Tribology - TriboBR 2014, November $3^{\text {rd }}$ to $5^{\text {th }}, 2014$, Foz do Iguaçu, PR, Brazil.
} 

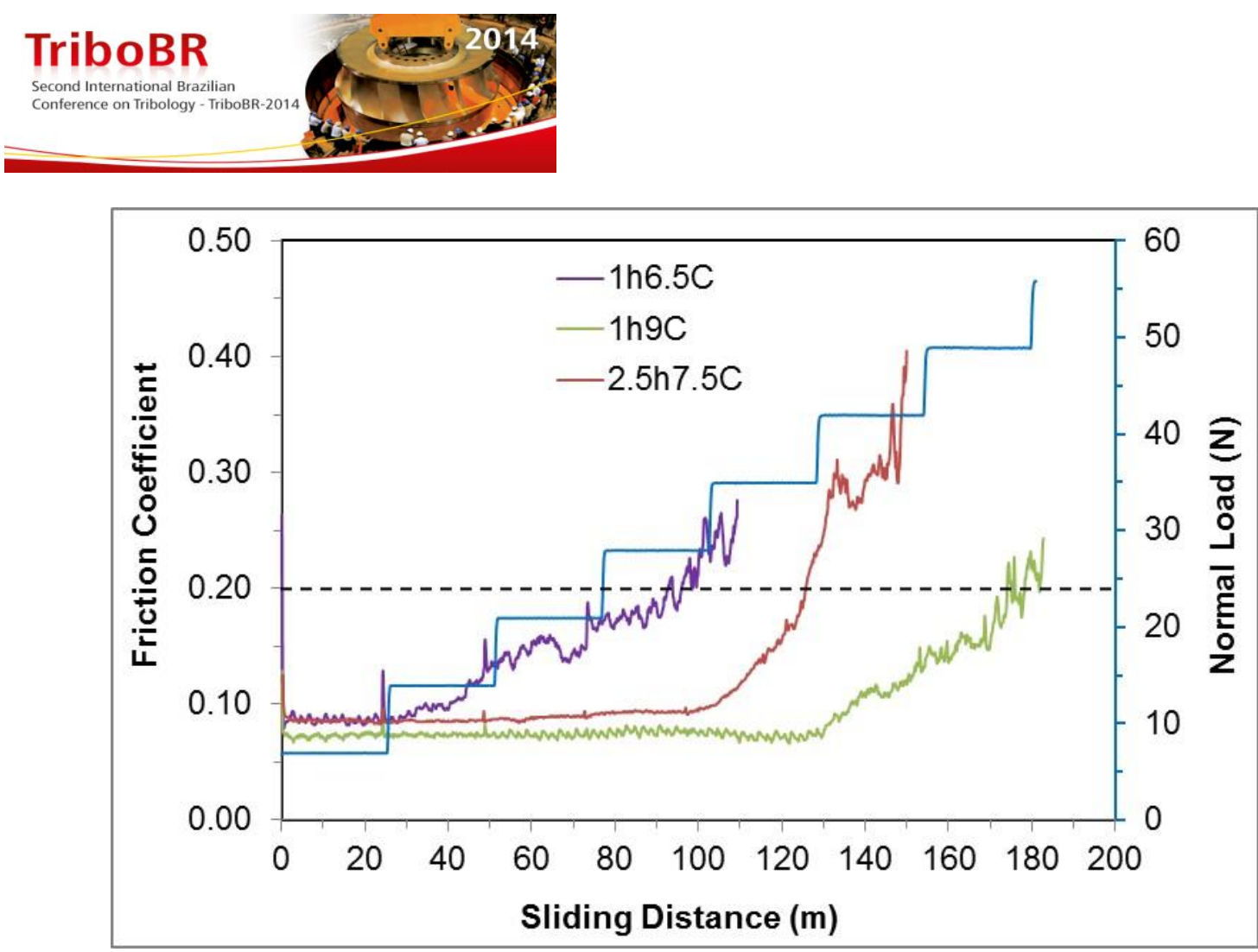

Figure 5 Typical evolution of friction coefficient with test time for two levels of total solid lubricant $(7.5$ and $10 \%)$ and two levels of $h-B N$ content (1\% and $2.5 \%)$.

It is clearly shown that the samples containing $10 \%$ of total solid lubricant content presented the best performance. Furthermore, between the samples with $10 \%$ of total solid lubricant, the samples containing $1 \%$ of $\mathrm{h}-\mathrm{BN}$ exhibited an improved performance.

The average results of the scuffing resistance tests of all composites can be observed in Figure 6. As mentioned previously, as the percentage of total solid lubricants increases, a substantial rise in the scuffing resistance is noticed. However, a decrease of this property was observed within the levels of total solid lubricant as the h-BN content increases.

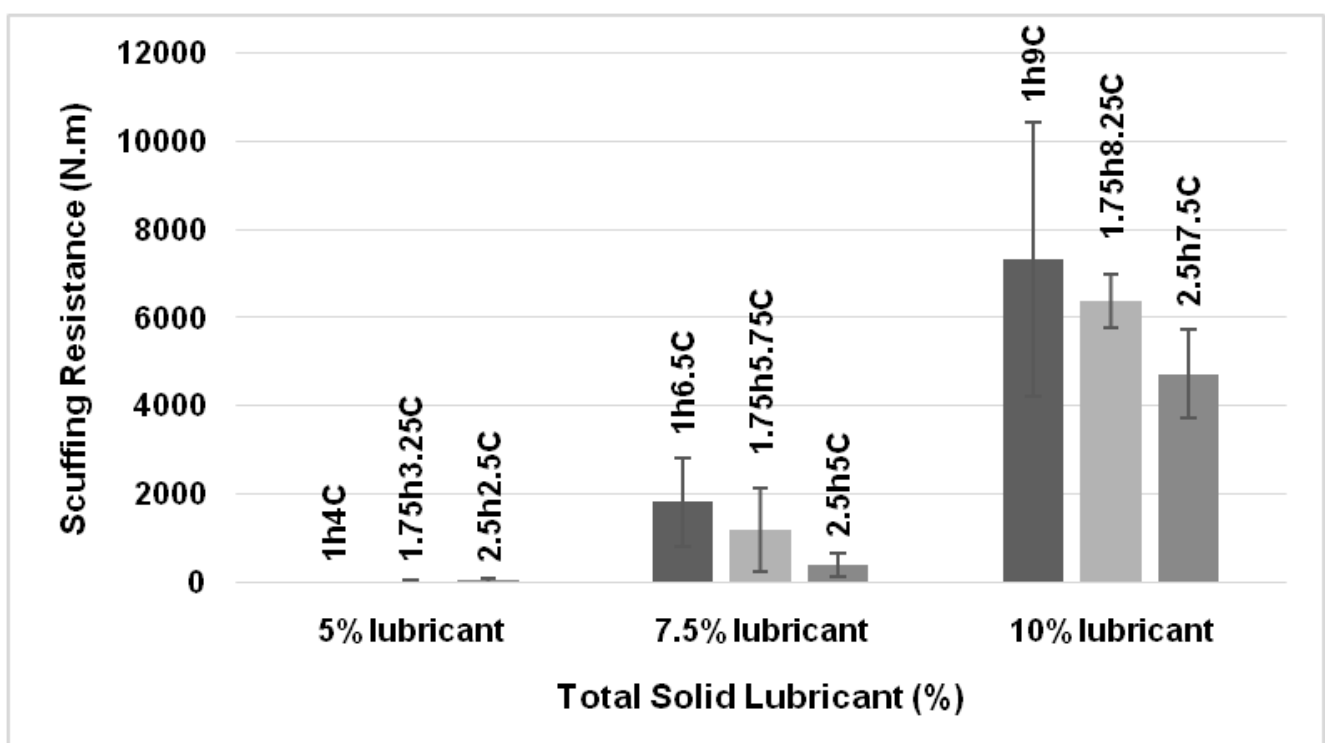

Figure 6. Scuffing resistance of sintered composites as function of h-BN content and total solid lubricant content.

\footnotetext{
* Technical contribution to the $2^{\text {nd }}$ International Brazilian Conference on Tribology - TriboBR 2014, November $3^{\text {rd }}$ to $5^{\text {th }}, 2014$, Foz do Iguaçu, PR, Brazil.
} 
In order to further understand the tribological system behavior, scuffing resistance tests were conducted and interrupted at different applied loads (14N and $35 \mathrm{~N})$. After the tests, the samples were ultrasonically cleaned in acetone for 15 minutes and the wear scars were analyzed. Topography images obtained by SEM, with secondary electrons (SE), are shown Figure 7. The images refer to wear scars resulting from reciprocating sliding tests interrupted at the normal load of $14 \mathrm{~N}$, within the lubricious regime $(\mu<0.2)$.

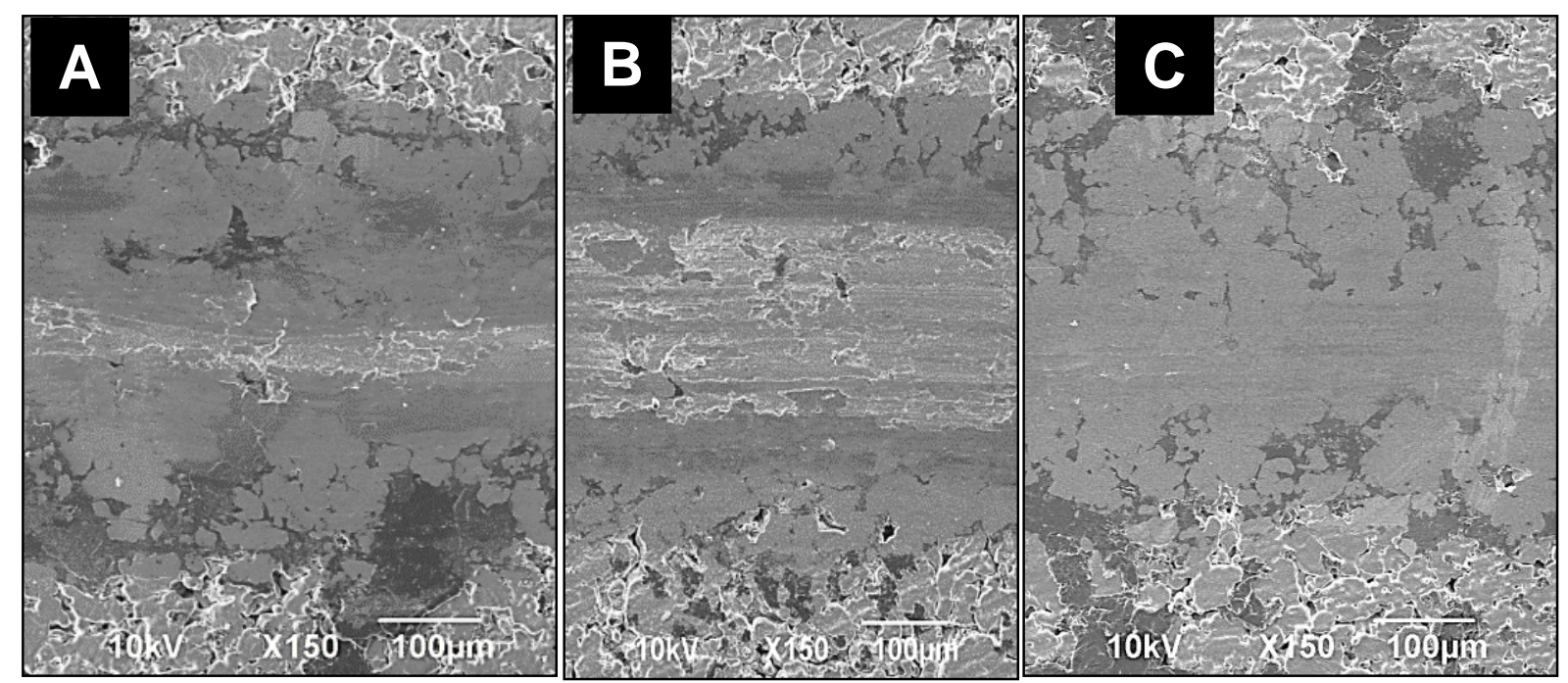

Figure 7. Typical wear scars of tests interrupted at $14 \mathrm{~N}$. A- sample 1h6.5C. B- 1h9C. C- $2.5 \mathrm{~h} 7.5 \mathrm{C}$.

The reservoirs of the solid lubricant are shown to have remained open inside the wear tracks after the sliding test. This effect, in principle, guaranteed the continuous re-supply of solid lubricants to the contact and, as a consequence, the formation of a tribo-layer indicated by the smooth, light-grey region, thus continuously maintaining the system in the lubricious regime $(\mu<0.2)$.

It is reasonable to suppose that the wear debris were continuously comminuted, deformed and oxidized thus forming the protective tribo-layer. This tribo-layer, in general, is formed by the elements from the sample, from the counter-body and from the environment. In addition, the presence of a tribo-layer decreases the direct contact area between the composite and the steel sphere. In this case, the tribo-layer consists of a mixture containing solid lubricants, which has a lamellar structure that allows, as a consequence, lower friction coefficients.

It can be observed that the sample $1 \mathrm{~h} 6.5 \mathrm{C}$ (Figure 7A) presented a degradation of the tribo-layer, characterized by a lighter track in the wear scar. For the sample 2.5h7.5C (Figure 7C), the degradation is at an initial stage. The composite 1h9C (Figure 7B) showed no evidence of degradation of the tribo-layer, in accordance with the scuffing resistance results, where this composite demonstrated the best friction coefficient behavior.

The wear scars of the samples tested at a normal load of $35 \mathrm{~N}$, are presented in Figure 8 . In these conditions the friction coefficient was above the lubricious regime $(\mu>0.2)$. The micrographs were obtained using backscattered electrons (BSE), and show the degradation of the tribo-layer for all the composites. However, in Figure 8B, remains of the gray tribo-layer (in detail) can still be observed, justifying the best performance of the composite $1 \mathrm{~h} 9 \mathrm{C}$ in terms of scuffing resistance.

\footnotetext{
* Technical contribution to the $2^{\text {nd }}$ International Brazilian Conference on Tribology - TriboBR 2014, November $3^{\text {rd }}$ to $5^{\text {th }}$, 2014, Foz do Iguaçu, PR, Brazil.
} 

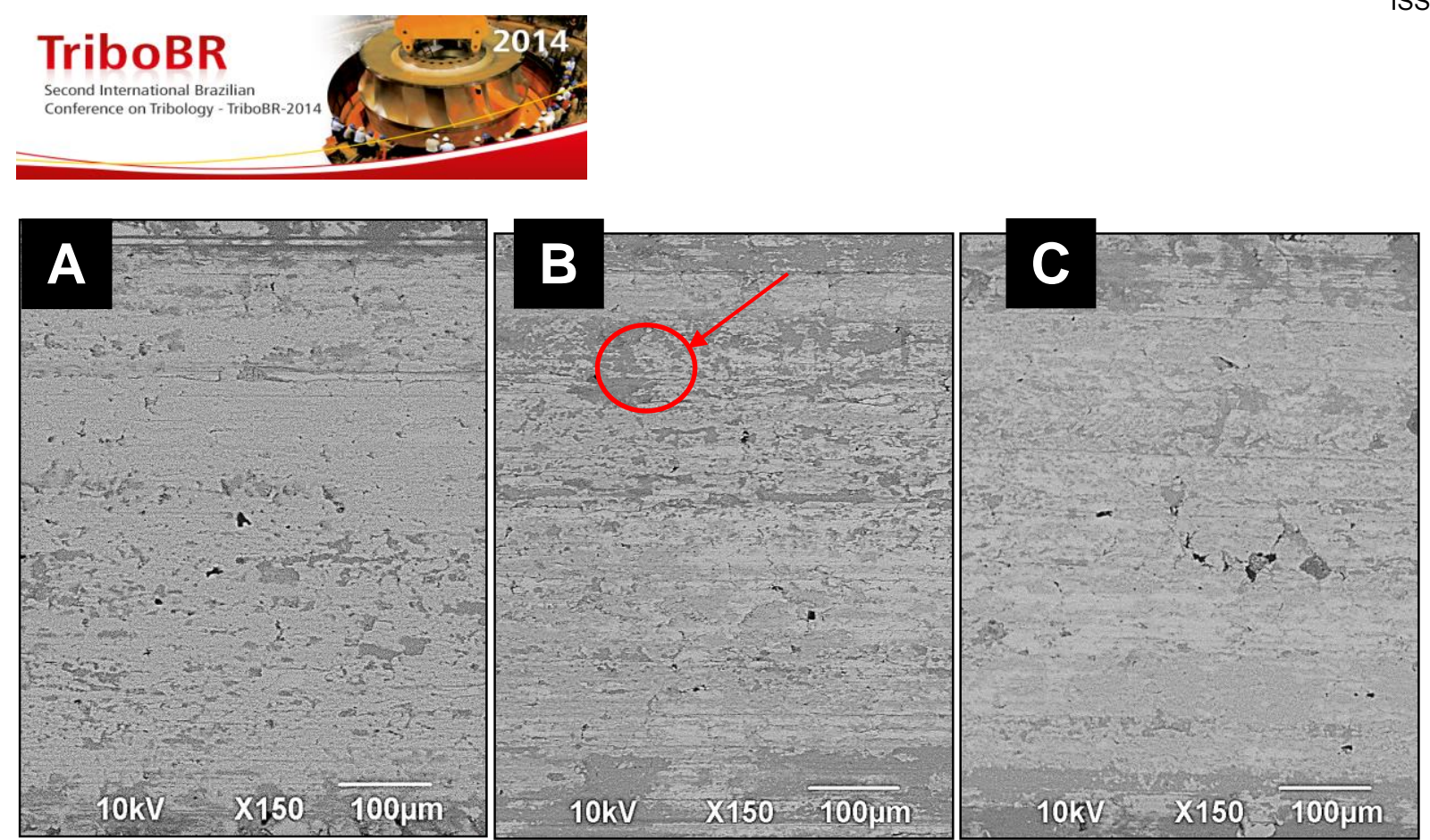

Figure 8. Wear scars at the end of the lubricious regime. A- 1h6.5C. B- 1h9C. C- 2.5h7.5C. SEM, BSE.

Figure 9 presents typical Raman spectra obtained in the central region of the wear scars of the samples after scuffing resistance tests, when interrupted at the normal load of $14 \mathrm{~N}$. There are three regions of different colors, meaning that there are different elements in the wear scars, according to the SEM analyze (Figure 9A). The black regions correspond to the reservoirs of solid lubricant, where characteristic Raman peaks of both graphite and h-BN were observed. In Figure $9 \mathrm{~b}$ the peak around $1360 \mathrm{~cm}^{-1}$ is attributed to h-BN [9,10], and the presence of graphite is confirmed by the spectrum showed in Figure 9C, with its characteristics peaks at $1590 \mathrm{~cm}^{-1}$ and $2730 \mathrm{~cm}^{-1}$, approximately [11]. The gray region corresponds to a mixture of the solid lubricants, as can be observed in Figure 9D. With the presence of graphite and h-BN peaks [9-11], it is reasonable to say that this is the basic tribolayer composition. The lighter region corresponds to the matrix, as shown in Figure $9 \mathrm{E}$. The behavior of the spectrum indicates a metallic material, and the presence of two small peaks related to carbon and/or h-BN indicates their presence. Finally, at the beginning of the same spectrum, there are peaks that can be attributed to the formation of iron oxide by a chemical reaction of the tribo-layer with the surrounding atmosphere. These peaks are positioned in the range of $225-450 \mathrm{~cm}^{-1}[12,13]$.

\footnotetext{
* Technical contribution to the $2^{\text {nd }}$ International Brazilian Conference on Tribology - TriboBR 2014, November $3^{\text {rd }}$ to $5^{\text {th }}$, 2014, Foz do Iguaçu, PR, Brazil.
} 

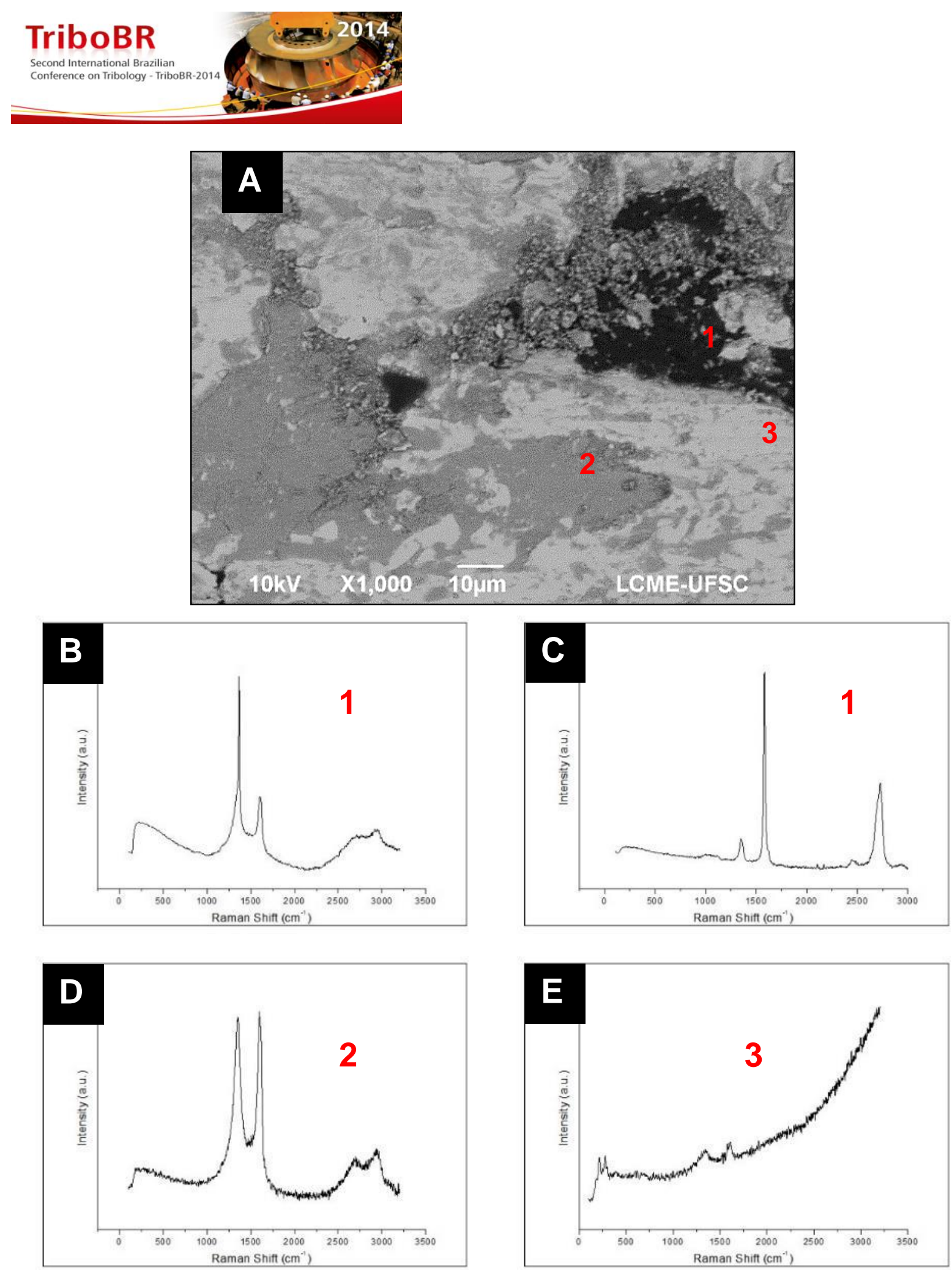

Figure 9. (A) Typical SEM micrograph of wear scar on lubricious regime. Related typical Raman spectra from wear scars: (B) and (C) typical spectra in dark region 1, (D) spectrum in gray region 2, (E) spectrum in light region 3.

\section{CONCLUSIONS}

a) The addition of solid lubricant greatly improved scuffing resistance of the selflubricating composites. However, the mechanical properties were detrimentally affected;

b) It was observed that decreasing proportions of $\mathrm{h}-\mathrm{BN}$ in the mixtures enhanced both tribological and mechanical properties;

* Technical contribution to the $2^{\text {nd }}$ International Brazilian Conference on Tribology - TriboBR 2014, November $3^{\text {rd }}$ to $5^{\text {th }}, 2014$, Foz do Iguaçu, PR, Brazil. 


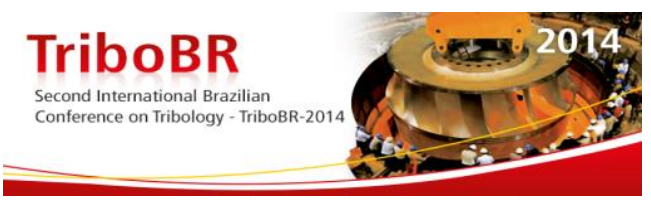

c) The composite presenting $1 \%$ in volume of $h-B N$ and $9 \%$ in volume of graphite presented the best results in terms of tribological properties, reaching values of 7000 N.m of scuffing resistance associated with $220 \mathrm{MPa}$ of tensile strength;

d) Further analysis of this improved composite during its lubricious regime evidenced the presence of a tribo-layer composed by both $\mathrm{h}-\mathrm{BN}$ and graphite, supplied by the solid lubricant reservoirs.

\section{Acknowledgments}

To CNPQ, CAPES, FAPESC, Whirlpool-Embraco and BNDES for the research funding. To Diego Salvaro, Deise Rebelo Consoni and Rafaela do Vale Pereira, whom helped with the sample characterization.

\section{REFERENCES}

1 Czichos H, Klaffke D, Santner E, Woydt M. Advances in tribology: the materials point of view, Wear, 1995; 190: 155-161.

2 Mahathanabodee S, Palathai T, Raadnui S, Tongsri R, Sombatsompop N, Effects of hexagonal boron nitride and sintering temperature on mechanicaland tribological properties of SS316L/h-BN composites, Materials and Design, 2013; 46; 588-597.

3 Rohatgi PK, Ray S, Liu Y. The Institure of Materials and ASM International, 1992; 37(3): 129.

4 Mello JD, C. Binder C, Binder R, Klein AN. Effect of precursor content and sintering temperature on the scuffing resistance of sintered self lubricanting steel, Wear, 2011; 271: $1862-1867$.

5 Donnet C, Erdemir A. Solid lubricant coatings: recent developments and future trends, Tribology Letters, 2004; 17 (3): 389-397.

6 Busch C. Solid Lubrication, Lubricants and Lubrication, 2007, Wiley-Vch, Weinheim.

7 Erdermir A. Review of engineered tribological interfaces for improved boundary lubrication, Tribology International, 2005; (38); 249-256.

8 G. Hammes, R. Schroeder, C. Binder, A. N. Klein, J. D. B. de Mello, "Effect of double pressing/double sintering on the sliding wear of self-lubricating sintered composites", Tribology International 2014; (70); 119-127.

9 Zhang WJ, et al. Nucleation, Growth and Characterization of Cubic Boron Nitride (cBN) Films, J. Phys. D: Appl. Phys, 2007; (40); 6159-6174

10 Arenal R, et al. Raman Spectroscopy of Single-Wall Boron Nitride Nanotubes, Nano Letters 6, 2006;Issue (8); 1812 - 1816.

11 Robertson J. Diamond-like amorphous carbon, Materials Science and Engineering 2002; (R37); $129-281$.

12 Crockett RM. et al. Wear and electrical resistance on diesel lubricated surfaces undergoing reciprocating sliding, Tribol. Lett. 2004;1(6); 187-194.

13 Ouyang M, Hiraoka $\mathrm{H}$. Structure and magnetic properties of iron oxide films deposited by Excimer laser ablation of a metal-containing polymer, Mater. Res.Bull., 1997; (32); 1099-1107.

\footnotetext{
* Technical contribution to the $2^{\text {nd }}$ International Brazilian Conference on Tribology - TriboBR 2014, November $3^{\text {rd }}$ to $5^{\text {th }}, 2014$, Foz do Iguaçu, PR, Brazil.
} 